\title{
El poder, el sujeto y la interpretación jurídica: un abordaje basado en el pensamiento tardío de Michel Foucault
}

The power, the subject and legal interpretation: an approach base on the later thought of Michel Foucault

Poder, sujeito e interpretação jurídica: uma abordagem a partir do pensamento tardio de Micbel Foucault

Pouvoir, sujet et interprétation juridique: une approche de la pensée tardive de Michel Foucault 权力主体和法律解释: 从迟来的思想出发米歇尔福柯 (Michel Foucault)

\section{Juan Emilio Ortiz ${ }^{1}$}

\section{Universidad Nacional de Rosario, Argentina}

Revista Derechos en Acción ISSN 2525-1678/ e-ISSN 2525-1686

Año 6/No 19 Otoño 2021 (21 marzo a 20 junio), 84-114

https://doi.org/10.24215/25251678e511

Recibido: 16/03/2021

Aprobado: 15/05/2021

Resumen: En sus últimas investigaciones, Michel Foucault propuso una ontología del presente, orientada a explorar el nudo constituido por tres ejes interrelacionados: el eje del saber, el eje del poder y el eje de la subjetividad. El presente trabajo pretende explorar las implicancias este

\footnotetext{
1 Profesor y Licenciado en Filosofía egresado de la Universidad Nacional de Rosario. Actualmente es becario del CONICET. Su lugar de trabajo es el IECH (instituto de estudios críticos en humanidades). Email: juane_ortiz@hotmail.com (ORCID: https://orcid.org/00000001-7213-3265)
} 
método para pensar la interpretación jurídica. El argumento analizará el conjunto de relaciones que intervienen en la constitución misma de una subjetividad. El régimen de verdad imperante en una sociedad contribuye a la formación de prejuicios, preconceptos y naturalizaciones, que condicionan la interpretación que se hace tanto de la realidad como de la estructura normativa. Siguiendo esta línea, el presente escrito permitirá desarrollar un enfoque que considere las relaciones e implicancias múltiples entre ciertas verdades a las que adscribe un sujeto (el magistrado) y el modo en que se transmiten al dictado de sentencias (que son interpretaciones). Procuraré mostrar que esta vía permite operar en un espacio muy sutil constituido entre el derecho positivo y la praxis interpretativa de los Magistrados. Entiendo que este análisis constituye una cuestión iusfilosófica de gran importancia cuyo tratamiento también le corresponde a la dogmática del derecho.

Palabras Claves: Derecho, Sujeto, Poder, Interpretación Jurídica, Régimen de Verdad, Foucault.

Abstract: In his latest research, Michel Foucault proposed an ontology of the present aimed at exploring the knot constituted by three interrelated axes: the axis of knowledge, the axis of power, and the axis of subjectivity. The present work aims to explore the implications of this method to think legal interpretation. The argument will analyze the set of relations that intervene in the very constitution of a subjectivity. The prevailing truth regime in a society contributes to the formation of prejudices, preconceptions, and naturalizations that condition the interpretation of both, reality and the normative structure. Following this line, this writing will allow to develop an approach that considers the multiple relationships and implications between certain truth to which a subject (the magistrate) ascribes and the way in which they are transmitted to the delivery of sentences (which are interpretations). I intend to show that this way allows operating in a very subtle space constituted between positive law and interpretative praxis of the magistrates. I understand that this analysis constitutes a very important ius philosophical question whose treatment also corresponds to the law dogmatic.

Keywords: Law, Subject, Power, Legal interpretation, Regime of truth, Foucault. 
Resumo: Em sua última pesquisa, Michel Foucault propôs uma ontologia do presente, com o objetivo de explorar o nó constituído por três eixos inter-relacionados: 0 eixo do conhecimento, 0 eixo do poder e 0 eixo da subjetividade. 0 presente trabalho pretende explorar as implicações deste método para pensar a interpretação jurídica. A argumentação irá analisar o conjunto de relações que intervêm na própria constituição de uma subjetividade. 0 regime de verdade vigente em uma sociedade contribui para a formação de preconceitos, pré-conceitos e naturalizações, que condicionam a interpretação que se faz tanto da realidade quanto da estrutura normativa. Nessa linha, esta redação permitirá o desenvolvimento de uma abordagem que considere as múltiplas relações e implicações entre certas verdades a que um sujeito (o magistrado) atribui e a forma como são transmitidas para a entrega de sentenças (que são interpretações). Tentarei mostrar que esse caminho permite operar em um espaço muito sutil constituído entre o direito positivo e a práxis interpretativa dos Magistrados. Entendo que esta análise constitui uma questão filosófica muito importante, cujo tratamento também corresponde à dogmática do direito.

Palavras-chave: Direito, Sujeito, Poder, Interpretação Jurídica, Regime da Verdade, Foucault.

Résumé: Dans ses dernières recherches, Michel Foucault a proposé une ontologie du présent, visant à explorer le nœud constitué de trois axes interdépendants: I'axe du savoir, l'axe du pouvoir et l'axe de la subjectivité. Le présent travail vise à explorer les implications de cette méthode pour réfléchir à l'interprétation juridique. L'argument analysera l'ensemble des relations qui interviennent dans la constitution même d'une subjectivité. Le régime de vérité qui prévaut dans une société contribue à la formation de préjugés, d'idées préconçues et de naturalisations, qui conditionnent l'interprétation faite à la fois de la réalité et de la structure normative. Suivant cette ligne, cette écriture permettra de développer une approche qui considère les multiples relations et implications entre certaines vérités auxquelles un sujet (le magistrat) attribue et la manière dont elles sont transmises à la délivrance de phrases (qui sont des interprétations). J'essaierai de montrer que cette voie permet d'opérer dans un espace très subtil constitué entre le droit positif et la praxis interprétative des magistrats. Je comprends que cette analyse constitue une question philosophique très importante dont le traitement correspond également à la dogmatique du droit. 
Mot-clés: Droit, sujet, pouvoir, interprétation juridique, régime de vérité, Foucault.

摘要: 在他的最新研究中米歇尔福 柯 (Michel Foucault) 提出了一 种当下的本体论旨在探索由三个相互关联的轴所构成的纽结: 知识 轴权力轴和主观轴. 本工作旨在探讨这种方法对法律解释的影响该 论点将分析干预主体性构成的一系列关系. 社会中普遍存在的真理 制度有助于形成偏见成见和归化从而限制了对现实和规范结构的解 释. 遵循这一思路本文将允许开发一种方法该方法考虑主题 (裁判 官)所归属的某些真相与它们传递到句子传递 (即解释)的方式之间 的多重关系和含意我将尝试表明这种方式可以在实证法与治安法官 的解释性实践之间构成的非常微妙的空间中运作我知道, 这种分析 构成了一个非常重要的哲学问题, 其处理方法也与法律教条相对应.

关键字: 法律, 主题, 权力, 法律解释, 真相制度, 米歇尔福柯.

\section{Introducción}

El presente escrito está motivado por la observación de que la dinámica del derecho positivo suele resultar insuficiente para sostener muchas conquistas logradas en materia de derechos humanos. Un ejemplo claro se encuentra en la selectividad discriminatoria que aun realiza el poder punitivo. Hace más de 200 años los códigos establecen que la acción penal sólo puede esgrimirse en función de los actos cometidos y no de las características del autor. No obstante, las sentencias judiciales siguen habilitando el poder punitivo dando muestras de una selectividad alarmante. En América Latina, la mayoría de las condenas recae sobre los ilegalismos de los sectores más vulnerables, es decir, la llamada "delincuencia de subsistencia" (Zaffaroni, 2020 , p. 8), estrechamente vinculada a la carencia de otros derechos de tipo social, económico y cultural. ${ }^{2}$ Esta situación,

2 El juez de la Corte Interamericana de Derechos Humanos, insiste en que las consideraciones que se hacen sobre la población carcelaria están atravesadas por la mirada de lo que él Ilama la "criminología mediática". Los medios de comunicación juegan con la imagen de que 
sumada al abuso de la prisión preventiva en la instancia procesal, se convierte en una forma velada de hacer cumplir un castigo de manera ilegal, es decir, una sentencia sin condena firme ni juicio previo (Art. $18 \mathrm{CN}$ ). Estas cuestiones muestran la fragilidad de los desarrollos en materia de derechos positivos. Los avances alcanzados en la tecnología normativa pueden ser insuficientes y convertirse en cualquier momento en retrocesos alarmantes. También pueden quedar anclados en la dialéctica de la administración diferencial de los ilegalismos (Cf. Foucault, 2008, p.316). En otros términos, castigo implacable para los más vulnerables, en un modo de producción que genera sistemáticamente pobreza, desigualdad, enfermedad y exclusión.

Ante estos casos cabe preguntarse ¿cuál es el punto singular a partir del cual giran algunas interpretaciones tendenciales, discriminatorias y hegemónicas que condicionan el funcionamiento de los dispositivos (legales, policiales, de salud, etc.)? ¿Qué operaciones, transformaciones, torsiones pueden ser precisas para minimizarlas en el mayor grado posible fortaleciendo una defensa integral de los derechos humanos?

En la presente ocasión, a exploraré el sentido de esas preguntas atendiendo al nudo sintomático que conforman el sujeto, el poder, y la interpretación jurídica. Son muchas las corrientes de filosofía del derecho que abordan este punto relacional ${ }^{3}$. Sin embargo, la argumentación que sigue procura

la mayor parte de los presos han cometido delitos graves contra la integridad humana. Pero esta idea es falsa: "La composición de la población carcelaria en la región demuestra que domina la prisionización por hechos que corresponden a la llamada delincuencia de subsistencia, lo que se confirma verificando que el porcentaje de presos por homicidios, delitos contra la integridad física y sexuales, por regla no suele superar el 20\% del total." (Zaffaroni, 2020, p. 8). Así lo corrobora la publicación de las estadísticas del Sistema Nacional de Información Criminal en Argentina. Con las políticas neoliberales (2018-2019) creció la tasa de delitos contra la propiedad (robos, hurtos) creció significativamente luego de un período de meseta. Los datos pueden consultarse en: https://www.argentina.gob.ar/seguridad/estadisticascriminales.

3 El profesor Rabbi Baldi destaca, en su reciente libro sobre la Interpretación jurídica, la teoría de Robert Alexy para dar cuenta de tres círculos que operan en el ámbito de las prácticas jurídicas: "el que se manifiesta entre la precomprensión del intérprete y el texto, 
evitar toda forma de esencialismo en la consideración de esas dimensiones para analizar la inmanencia e historicidad en juego entre las mismas. En otras palabras, se insistirá en el carácter sobredeterminado de estas instancias, con el fin de mostrar las influencias recíprocas entre un régimen jurídico-político, la constitución de subjetividad, los juicios que esta emite y las decisiones que aprueba o rechaza. Para abordar estas cuestiones, me ceñiré a los desarrollos del último Foucault sobre todo en lo que se refiere a la constitución de la subjetividad dentro de un régimen de verdad. Creo que a través de estas ideas, el francés procuró exceder los límites de la tradicional noción del sujeto de derecho (concepción que responde a la doble herencia del iusnaturalismo y del iuspositivismo) sugiriendo un diálogo necesario y urgente entre el derecho y la ética. ${ }^{4}$

\section{Genealogía de la tipicidad jurídica}

\section{II.1. Más allá del iusnaturalismo y del iuspositivismo}

En virtud de lo anterior, es preciso comenzar el análisis mostrando el vínculo entre el derecho y las relaciones sociales. El pensamiento foucaulteano se orienta a realizar una genealogía de las instituciones (el derecho entre ellas), señalando la historicidad de las entidades jurídicas y su vínculo con un

\footnotetext{
el que vincula las normas al sistema jurídico, y el que relaciona a aquellas con los hechos. Ahora bien, mientras los dos últimos se hallan ya planteados, en esencia, en las tradiciones del positivismo jurídico y de la razón práctica, respectivamente, el primero pertenece, en puridad a la hermenéutica filosófica y constituye, según creemos, su gran aporte al proceso de determinación del derecho." (RABBA, Baldi, 2020, p. 212). El profesor Manuel Atienza adscribe a una postura similar al considerar las interacciones entre cinco dimensiones en la racionalidad legislativa. La articulación de las mismas se produce a partir de un principio de razón práctica deudor de la ética de la comunicación de Habermas (ATIENZA, 2019, p.65).

4 Esta es una línea abierta por Foucault cuando señala: "tengo la impresión de que en el pensamiento político del siglo XIX -y quizás hiciera falta remontarse más lejos, a Rousseau y Hobbes-, se ha pensado el sujeto político esencialmente como sujeto de derecho, ya sea en términos naturalistas, o bien en los términos del derecho positivo. En cambio, me parece que la cuestión de! sujeto ético es algo que no tiene mucha cabida en el pensamiento político contemporáneo." (FOUCAULT, (1999). p. 407).
} 
conjunto de relaciones de poder. Esta vía permite mostrar los factores epistémicos, políticos y económicos que confluyen en la formación de lo que en derecho se conoce como tipos legales. Si bien es cierto que Foucault no utilizaba esta terminología técnica, un breve repaso de su método de reflexión puede mostrar la pertinencia de la relación y también ayudar a la teoría jurídica a vincularse de otro modo con la tipicidad.

Un ejemplo claro de esta cuestión se encuentra a lo largo del texto Vigilar y Castigar. Allí se analiza la variación entre el contenido de las formas penales en el medioevo y los cambios producidos con el desarrollo de nuevas pautas sociales surgidas a partir del siglo XVIII. En ese texto, el autor muestra que los cambios en las relaciones de fuerzas se traducen en variaciones que afectan a las conductas penadas, a los procedimientos de la intervención jurídica y también a las identidades a las que se aplican. Si en el Antiguo Régimen la descarga punitiva ocurría como respuesta a un desafío esgrimido ante el poder del soberano, en la Modernidad, el delito pasará a relacionarse con una conducta anómica que altera la dinámica del trabajo y la riqueza en el modo de producción capitalista:

Con las nuevas formas de acumulación del capital, de relaciones de producción y de estatuto jurídico de la propiedad, todas las prácticas populares que dimanaban, ya bajo una forma tácita, cotidiana, tolerada, ya bajo una forma violenta, de ilegalismo de los derechos, se han volcado a la fuerza sobre el ilegalismo de los bienes. El robo tiende a convertirse en la primera de las escapatorias de la legalidad (...) la economía de los ilegalismos se ha reestructurado con el desarrollo de la sociedad capitalista. (Cf. Foucault, 2008, p.100).

En este proceso también se ven alterados los modos de castigo. Una sociedad capitalista ya no necesita descuartizar o incendiar a un supuesto infractor ${ }^{5}$, sino estimular la vida

5 Es preciso insistir en el carácter de "supuestos infractores", ya que gran parte de la punición en la Edad Media estuvo orientada por los delirios misóginos del Malleus Malleficarun 
(reproducción del proletariado) y disciplinar los cuerpos (normalizarlos) para hacerlos producir de la manera más eficiente. El objetivo de la intervención punitiva estará ahora orientado a operar en el origen de la conducta infractora (en el interior del individuo) para evitar que se produzca y, en lo posible, encauzarla hacia la normalidad. La prisión aparece como el modelo típico ideal de esa institución disciplinaria entre otras: la escuela, las fábricas, los hospitales, las instituciones psiquiátricas.

Foucault se alejaba de cualquier ideal de trascendencia para la definición de aquellas unidades discursivas en relación a las cuales se desarrolla la acción institucional. Sus trabajos apuestan a dejar en suspenso las fundamentaciones universales para poner en su lugar una descripción de cómo surgen las tipologías en una trama de relaciones sociales. El objeto de aquellas categorías tales como delincuente o enfermo mental no tienen una entidad substancial e invariable para cualquier tiempo y lugar. Por el contrario, se encuentran vinculadas a prácticas efectivas vigentes en un momento específico: "Lo que be querido mostrar es como el sujeto se constituía a sí mismo, de tal o cual forma determinada, como sujeto loco o sano, como sujeto delincuente o no delincuente, a través de un determinado número de prácticas, que eran juegos de verdad, prácticas de poder." (Foucault, 1999, p. 403).

De acuerdo con lo anterior, si tuviera que situar a Foucault en el debate entre el iusnaturalismo y el iuspositivismo, diría que no es posible inscribir sus ideas de manera definitiva en alguna de esas categorías. ${ }^{6}$ Quizá una buena estrategia para aclarar este punto consiste en recurrir a un concepto

que llevaron a la tortura y condena a muerte a gran cantidad de mujeres inocentes acusadas de brujería.

6 La cantidad de bibliografía para abordar el tema del iusnaturalismo y del iuspositivismo puede ser muy amplia. Creo que para una caracterización de ambas posturas en relación al problema de la interpretación puede consultarse un trabajo muy reciente del profesor RABBI, Baldi (2020). Interpretación Jurídica. Teoría y práctica jurisprudencial . En las primeras páginas del libro el autor realiza de modo sintético una buena exposición de los principales tópicos del positivismo, seguidamente hacer lo propio con las principales corrientes del derecho 
que acuña Paul Veyne para referirse a ese dilema generado por el pensamiento foucaulteano. El historiador dirá que en Foucault opera una especie de positivismo hermenéutico. Con esa noción paradójica pretende dar cuenta del método particular desarrollado por el filósofo. En cierta forma, sería positivista desde el momento en que no se puede conocer con una certeza metafísica nada sobre el yo, el mundo, el bien. (Cf. Veyne, 2014, p. 24). No obstante, y por las consecuencias de esta misma racionalidad, su enfoque sería también hermenéutico ya que, como señala Veyne: "no bay experiencia que no sea un modo de pensar. Los hechos históricos pueden no ser independientes de las determinaciones concretas de la bistoria social, pero, pese a ello, el hombre sólo puede experimentarlas a través del pensamiento." (Veyne, 2014, p. 24). ${ }^{7}$

Por consiguiente, a diferencia del iusnaturalismo (sobre todo en su vertiente Moderna), una mirada foucaulteana o genealógica tiende a mostrar que no sería posible definir un contenido originario o trascendente para ciertas tipologías o procesos. Los tipos no caen del cielo, sino que son el resultado de tensiones socio políticas en el seno de una cultura determinada. No se postula nada equiparable a un fundamento para definir el ser substancial de una identidad o el contenido de un tipo legal. Por el contrario, se realza una perspectiva relacional que describe el movimiento incesante y discontinuo de las convenciones sociales. Más que mostrar una esencia o un objeto ya consumado, la lógica de este planteo muestra los juegos estratégicos de relaciones a través de las cuales algunas costumbres

natural, para finalmente anudar ambas perspectivas desde una mirada hermenéutica de la interpretación jurídica deudora de la filosofía de Gadamer.

7 Además del trabajo citado en la nota anterior, el profesor español Rodríguez Puerto explica, en un trabajo titulado Métodos de interpretación, hermenéutica y derecho natural, el vínculo existente entre el derecho natural y la teoría hermenéutica. El autor señala que atender a un contexto social implica el reconocimiento de cuestiones que exceden la pretendida facticidad del texto legal. Hay una realidad social que influye en la elaboración de las reglas, pero que también "forman parte del ámbito de precomprensión que colabora en la decisión interpretativa del jurista" (Cf. RODRIGUEZ, Puerto (2010). p. 339-340). 
y prácticas derivan en tipos y desde allí se deduce una norma que llega a pensarse como deber ser. ${ }^{8}$

Por otra parte, y a diferencia del iuspositivismo, la genealogía permite evitar una separación apresurada entre el derecho y los supuestos morales, políticos e ideológicos que condicionan de manera inevitable la formación de las leyes y la interpretación de las mismas. Este modo de reflexión también tiene efectos para la praxis jurídica que conducen a mostrar el carácter político y, por qué no, ideológico de las decisiones judiciales. En este sentido, cabe recordar que para Kelsen: "La teoría pura del derecho se esfuerza por eliminar este elemento ideológico al brindar una definición de la norma jurídica totalmente independiente de la noción de norma moral y afirmar la autonomía del derecho respecto de la moral" (Kelsen, 2009, p. 53).

\section{II.2. Genealogía y derecho humanos}

Así, la distancia del método de Foucault tanto con respecto al iuspositivismo como respecto al iusnaturalismo puede ofrecer una lección innovadora para la teoría del derecho. Su modo particular de razonar invita a pensar un anudamiento entre los elementos de ambas posiciones al tiempo que las excede, evitando que la reflexión quede cancelada en presupuestos parciales sobre la esencia del derecho. Siguiendo esta lógica, no existiría una norma pura u originaria (ya sea natural o positiva) sobre la cual se efectuaría luego una interpretación adecuada o inadecuada. Por el contrario, el derecho mismo ya sería una interpretación (Medici, 2009, p. 188), un punto de vista institucionalizado acerca de una realidad que parece no tener un

\footnotetext{
8 Para la conceptualización de la noción de tipo penal estoy siguiendo la noción del Manual de Derecho Penal de los Dres. Zaffaroni, Alagia y Slokar. Allí se describe esta dialéctica singular entre la definición de un tipo y la norma que se deduce de él: "el derecho pena, para reducir las hipótesis, debe valorar acciones como prohibidas o no prohibidas. Para ello, de los tipos deduce normas: del art. 79 deduce no matarás, del art. 162, deduce no hurtarás, etc. En este sentido la norma es un instrumento de lógica jurídica" (ZAFFARONI, Raúl Eugenio (2006). et al., p. 344-345).
} 
sentido unívoco, sino constituir un campo de posiciones diversas que se entrelazan en una tensión continua.

En este punto, es preciso alejarse de interpretaciones ya obsoletas y limitadas que reducen su teoría a un relativismo irracional o a un rechazo anárquico del derecho y las instituciones. La inexistencia de una norma pura no debe confundirse con la ausencia de un respeto por la dignidad humana. Como prueba palpable de esto último, basta recordar que en el año 1981, en Ginebra, pronunciaba palabras memorables en defensa de los derechos humanos:

Existe una ciudadanía internacional que tiene sus derechos, sus deberes, y que nos compromete a levantarnos contra todo abuso de poder, cualquiera que sea su autor y cualesquiera que sean sus víctimas (...) El sufrimiento de los hombres nunca debe ser un mudo residuo de la política, sino que, por el contrario, constituye el fundamento de un derecho absoluto a levantarse y a dirigirse a aquellos que detentan el poder. (Foucault, 1996 b, p. 211).

Este tipo de expresiones muestra claramente que la reflexión del autor no tiene una inspiración de rechazo absoluto ante una dinámica institucional. Por el contrario, se presenta como una invitación a pensar las herramientas institucionales con un sentido realista y con mucha prudencia. ${ }^{9}$ Es indiscutible que las instituciones tienen la potencialidad de hacernos vivir un poco mejor y encuentran su asiento en un deseo de estabilidad indispensable para el desarrollo de nuestras vidas. No pretendo idealizar los alcances del dispositivo jurídico, pero no creo que sea prudente confundir la dominación, la opresión y la normalización con la substancia misma del derecho, o reducir a este último a ser siempre un mero efecto de un

9 Cuando empleo el termino realista en el presente escrito, me refiero a una consideración integral de los entes en cuestión, es decir, considera tanto la dimensión lógica y ontológica como la dimensión óntica. En otras palabras, una tal concepción, atiende a la sobredeterminación compleja de factores políticos, ideológicos, económicos y subjetivos que se anudan de un modo singular en cada situación concreta. 
poder perverso. Foucault solía aclarar cuando lo entrevistaban que "no toda relación de poder se limita a constreñir y a forzar" (Foucault, 1999, p. 118). Hay, de hecho, modos positivos y placenteros de experimentar relaciones de influencia. (Cf. Foucault, 2016, p.151; Cf. Foucault, 1999, p. 413). Del mismo modo, se puede pensar que hay formas positivas y deseables de ejercer el derecho. Por ejemplo, cuando Zaffaroni distingue entre poder jurídico y poder punitivo, y señala que el poder jurídico debería contener o moderar los excesos de la pulsión de policía, se puede hablar de un uso razonable de la tarea judicial. (Zaffaroni, 2020 b, p. 79-80). El problema es que el paradigma neoliberal, como cualquier forma de dominación, conduce a identificar sin más al poder jurídico con el poder de policía, una cuestión que ya advertía Foucault en Nacimiento de la biopolítica. La competencia como principio rector de la dinámica económica encuentra en el brazo judicial un modo de administrar el conflicto que genera la desigualdad (Cf. Foucault, 2007 b, p. 211). Y un problema aún mayor es que los jueces, los medios de comunicación y la opinión mayoritaria se toma muy en serio esta creencia y no se cuestiona los efectos de exclusión que la misma produce.

Por consiguiente, si bien es cierto que no toda relación de poder es negativa, es preciso advertir que existen momentos en que estas posiciones de influencia se mantienen fijas y cancelan el flujo dinámico de los agentes sociales que ejercen y sufren esas relaciones. Reflexionar acerca de la estructura institucional y las técnicas gubernamentales es de vital importancia ya que ellas intervienen directamente en la consolidación o la minimización de estos estados de dominación: "El análisis de estas técnicas es necesario porque, con frecuencia, a través de este género de técnicas es como se establecen y se mantienen los estados de dominación" (Foucault, 1999, p. 414).

Así, el peligro de la dominación se materializa cuando el juego de la verdad y el poder queda suturado y fijo en torno a prácticas e identidades que se imponen como definitivas, 
inmutables y trascendentes. Por esa razón, no se trata de negar la norma, sino de advertir cuando la misma se ampara en fundamentaciones ideales o cuando transgrede de modo ilegítimo el terreno de la universalidad. Allí se encuentra un punto clave de la moral teórica foucaulteana: "Ser respetuoso cuando una subjetividad se subleva e intransigente desde que el poder transgrede lo universal" (Foucault, 1999, p. 207). Es posible afirmar entonces que el peligro no radica en la función misma de los tipos legales que resultan convenientes para organizar una tarea gubernamental $^{10}$, sino en mantener un vínculo idealista con los mismos, que encubra su carácter de ficciones jurídicas y su vínculo con relaciones de poder. En los tiempos actuales, en que los Estados y las personas se encuentran bajo el yugo de un capitalismo financiero agresivo, en que no resultan cuestionadas formas de enriquecerse y de acumular la propiedad que se perciben como naturales, evidentes e incuestionables, es preciso que el ejercicio del derecho se oriente a cuestionar críticamente y evitar, en el mayor grado posible, esas configuraciones dominantes en las técnicas gubernamentales que perjudican el desarrollo integral de personas y comunidades.

\section{Subjetividad e interpretación}

\section{III.1. Régimen de verdad: inclinación del sujeto ante lo verdadero}

Ahora bien, esta tendencia a la dominación señalada más arriba, no se manifiesta sólo en las fundamentaciones trascendentales que subyacen a las prácticas normativas, sino también en el vínculo constitutivo que el sujeto mantiene con aquellas verdades en las que cree firmemente y sedimentan su constitución en sus tramas más singulares e íntimas. Por esta razón, en sus últimas reflexiones, Foucault se enfoca en el nudo que

10 “Como no puede averiguarse si algo está prohibido sin partir de una previa definición de lo prohibido, el tipo penal siempre es lógicamente necesario." (ZAFFARONI, Raúl Eugenio (2006). et al, 2006, p. 346). 
se produce entre los saberes, las relaciones de poder y la constitución de la subjetividad. En el año 1984 el filósofo reparaba en que una adecuada ontología del presente tenía que ser capaz de articular estos tres niveles de reflexión. (Cf. Foucault, 1996, p. 109). Cuando se analiza una relación de poder sólo desde el aspecto de la institución política y se excluyen las complejas relaciones de cada individuo consigo mismo y con los demás, la reflexión puede quedar encasillada en las consideraciones formales de un sujeto de derecho. Así, interrogado acerca de la relación de sí como punto estratégico para una resistencia política, Foucault respondía:

"si se intenta analizar el poder no a partir de la libertad, de las estrategias y de la gubernamentalidad, sino a partir de la institución política, sólo es posible considerar al sujeto como sujeto de derecho. Estaríamos ante un sujeto dotado o no de derechos y que, mediante la institución de la sociedad política, los ha recibido o perdido: con ello se remite a una concepción jurídica del sujeto. En cambio, la noción de gubernamentalidad permite, eso creo, hacer valer la libertad del sujeto y la relación con los otros, es decir, lo que constituye la materia misma de la ética" (FOUCAULT, Michel,1999, p. 414).

Los trabajos sobre Foucault y el derecho suelen dejar de lado la cuestión subjetiva, desconociendo esta precisión metodológica de sus últimos textos, pero además omitiendo el hecho de que las técnicas de gobierno se ejercen mediante la articulación de este nudo. En consecuencia, la minimización de los estados de dominación sólo puede surgir de un trabajo que articule esos tres niveles de reflexión, atendiendo a la efectividad de las relaciones de poder. Unas líneas antes del fragmento citado, Foucault expresa literalmente esta cuestión cuando afirma:

El problema no consiste, por tanto, en intentar disolverlas [a las relaciones de poder] en la utopía de una comunicación perfectamente transparente, sino en procurarse las reglas de derecho, las técnicas de gestión y también la moral, el ethos, la práctica de sí, que permitan 
en estos juegos de poder, jugar con el mínimo posible de dominación (Foucault, 1999, p. 412).

El presente escrito se presenta como una exploración en este sentido, ya que intenta mostrar el punto de confluencia de este nudo en el desarrollo de las decisiones judiciales. Creo que el ámbito de la interpretación jurídica es el punto crucial en el que se manifiesta esta articulación entre las reglas del derecho y la cuestión ética en el sentido en que la entiende Foucault, esto es, como una reflexión acerca de la propia libertad y de la de los demás, estando las personas atravesadas por relaciones de influencia. Por esa razón, cuando hablo de ética en relación al derecho, no propongo nada parecido a esa postura que asusta a muchos juristas y que apuntaría a someter la práctica jurídica a valores morales sobre los que no puede existir un consenso absoluto. Más bien, hago referencia a pensar reglas de derecho que puedan facilitar la vida en libertad, reconociendo la singularidad de los actores sociales y evitando, en el mayor grado posible, dinámicas excluyentes y opresivas en los dispositivos. De allí se deriva la importancia de definir claramente una concepción del sujeto como punto irreductible de toda interpretación y el vínculo que establece con los juegos de verdad en los que se constituye.

En primer lugar, es preciso señalar que al hablar de sujeto en la perspectiva foucaulteana no se hace referencia a nada parecido a una esencia, sino a un pliegue singular que articula múltiples relaciones. No hay subjetividad en la forma de una experiencia originaria o fundamentada por algún universal antropológico ya sea de manera a priori o trascendente. El filósofo muestra que eso que llamamos sujeto emerge como efecto de un régimen de verdad que actúa como una fuerza constitutiva de las decisiones y pensamientos de un individuo. Así, la subjetividad estaría caracterizada por el lazo entre la vida de este y la fuerza de los saberes y prácticas que se le imponen como verdad: "la subjetividad se concibe como lo que se constituye y se transforma en la relación que tiene con su propia 
verdad. No hay teoría del sujeto independiente de la relación con la verdad" (Foucault, 2020, p. 28) ${ }^{11}$.

En segundo lugar, esta noción de régimen no consiste en una ley, una prohibición o una ideología que coacciona a una substancia subjetiva dada de antemano. Por el contrario, un régimen se configura a partir de una serie de relaciones jurídicas y políticas que se anudan de manera inmanente con las tramas vitales del propio individuo. Creo que se encuentra aquí un proceso complejo y circular que conduce a pensar en la sobredeterminación entre ciertas tipologías legales, la formación de los sujetos y conformación matrices de interpretación. El propio Foucault da cuenta de este proceso cuando describe el modo en que las personas quedan ligadas a una forma específica de reproducir determinadas verdades:

ese régimen de verdad, por el cual los hombres quedan atados a la necesidad de manifestarse como objeto de verdad, está ligado a regímenes políticos, jurídicos, etc. En otras palabras, la idea sería que, de lo político a lo epistemológico, la relación por establecer no debe serlo en términos de ideología, y tampoco en términos de utilidad. No debe hacerse a través de nociones como las de ley, prohibición, represión, sino en términos de régimen, de regímenes de verdad articulados con regímenes jurídico-políticos (Foucault, 2014, p. 125).

En este sentido, es claro que existe un sometimiento del sujeto a cierta fuerza de lo verdadero. No obstante, no es un sometimiento "impuesto", sino constitutivo y, por ende, aceptado "libremente" por el individuo. No se deriva del contenido positivo de los saberes, sino que actúa a la manera de un presupuesto subyacente. No tiene que ver con la deducción lógica que liga a las premisas con una conclusión, pero si con la aceptación de reglas de juego que no se cuestionan, a la manera de

11 El régimen penal por ejemplo consistiría en "el conjunto de los procedimientos e instituciones que comprometen, determinan, obligan a los individuos a someterse a leyes de alcance general" (FOUCAULT, Michel, (2014). p. 116). 
una especie de compromiso o profesión de fe (Foucault, 2014, p. 119). Estas reglas de juego, en última instancia, son contingentes y cambiantes, pero al encontrarse operando en múltiples prácticas se tornan incuestionables. Es precisamente allí donde radica la fuerza y la naturalidad con la que se impone un régimen: "Es esto, lo verdadero mismo, lo que determina su régimen; es lo verdadero mismo lo que constituye la ley y es lo verdadero mismo lo que me obliga. Es verdadero y yo me inclino. $Y$ me inclino porque es verdadero y me inclino en la medida en que lo es" (Foucault, 2014, p. 118). Aquel que no acepta este régimen de verdad es juzgado precisamente como un loco: "No puede haber voz de la locura en la filosofía ni en ningún otro sistema racional. No puede haber locos, esto es, no puede haber gente que no acepte el régimen de verdad" (Foucault, 2014, p. 122).

Este análisis permite suponer que esta fuerza de loa verdadero condiciona tanto las técnicas de gobierno como las interpretaciones normativas. Por esta razón, el individuo se convierte en el agente activo de una verdad. En sus últimos trabajos Foucault advertía que los modos de dominación modulan procesos institucionales externos con prácticas a través de las cuáles el individuo actúa sobre sí y, por ende, en relación a los demás. El filósofo sostenía que sus investigaciones anteriores sobre las prisiones, los asilos, las fábricas, etc., se veían limitadas al no incluir esta dimensión:

Cuando yo estudiaba los asilos, las prisiones y demás, insistía tal vez demasiado en las técnicas de dominación. Lo que podemos llamar 'disciplina' es algo en verdad importante en este tipo de instituciones, pero no es más que un aspecto del arte de gobernar a la gente en nuestra sociedad. (...) El poder está hecho de relaciones complejas: esas relaciones involucran un conjunto de técnicas racionales, cuya eficacia proviene de una aleación sutil de tecnologías de coacción y tecnologías de $s \hat{\imath}$ (Foucault, 2016, p. 45-46).

Creo que estas ideas muestran la materialidad del nudo conformado entre las verdades a las que adscribe un sujeto, las identidades a las que se aferra y las prácticas políticas y 
jurídicas que promueve o rechaza. No tiene demasiado sentido un método que considera sólo una parte de ellas y deja de lado otros aspectos de este conjunto de relaciones. Por consiguiente, si se desea ejercer con responsabilidad una tarea de gobierno, el estudio no debe orientarse únicamente a la aplicación de las reglas del derecho positivo, sino también a concebir la relación de las mismas con un régimen de verdad y la interpretación que, inmerso en él, hacen los agentes sociales.

Ahora bien, todo lo anterior conduce a preguntarse, ¿A partir de qué concepción de la verdad los individuos ejercen su libertad?; ¿Qué ideas sobre la propia identidad guían la relación que se establece con uno mismo y con los demás?; ¿qué pasa cuando una verdad que el sujeto tiene acerca de sí adquiere el carácter de una identidad inmutable y se juzga a los demás desde un presupuesto similar?

Es importante meditar sobre estas preguntas. En efecto, allí se ponen en juego actitudes que conducen a la sumisión absoluta ante un régimen naturalizado y a la reproducción pasiva de las diferencias que promueve. Estas ideas permiten deducir que hay factores subjetivos (entiéndase bien, que hacen a la constitución del sujeto en un régimen de relaciones de verdad) que se filtran de manera constitutiva en la interpretación de las normas, a la manera de verdades inconscientes, que el sujeto no puede entrever si no media un proceso de crítica profundo. Cabe aclarar que "inconsciente" no se relaciona aquí con algún fondo instintivo oculto o reprimido, sino con la ceguera respecto a la constitución efectiva de los juegos de verdad. Desde luego que este asunto reviste una gran complejidad, ya que existe una implicación afectiva de los individuos con esos regímenes que orientan nuestra vida. Es muy difícil desprenderse de sentidos impuestos a los que nos aferramos en la búsqueda de un sentimiento de previsibilidad y seguridad (esta es, por otra parte, la condición mínima que se anhela mediante el trazado de una normativa).

Muchas veces, antes que interrogarnos acerca de la contingencia de nuestras creencias resulta más cómodo ampararse 
en sentidos impuestos, que acrediten la fuerza de una certeza indiscutible y que nos sirva como principio rector de nuestras acciones y juicios. El peligro de esta sumisión ante lo naturalizado es que la defensa acérrima de estas verdades e identidades impide un adecuado ejercicio de transformación propia y obtura un efectivo reconocimiento del otro en su alteridad, su singularidad y sus necesidades. En una apretada síntesis, temo la transformación, rechazo la alteridad porque, en suma, temo y no acepto la pérdida o la puesta en cuestión de lo que yo mismo soy, de lo que tengo y de lo que creo ser. Este vínculo estrecho entre la relación de sí y la relación con los otros constituye otro de los tópicos tematizados por Foucault en el último tramo de su investigación:

podemos preguntarnos, por ejemplo, cómo se formaron con referencia a la locura, con referencia a la enfermedad, con referencia al crimen, tipos de prácticas que implicaban, la existencia y el desarrollo de discursos veraces sobre la razón alienada, el cuerpo enfermo o el carácter criminal y de qué manera la relación que tenemos con nosotros mismos - y entiendo por relación con nosotros mismos no simplemente la que tenemos con nuestra propia individualidad, sino la relación que tenemos con los otros en cuanto son también nosotros mismos- se ve afectada, modificada, transformada, recorrida por la existencia de ese discurso verdadero y los efectos que produce, por las obligaciones que impone y las promesas que sugiere o formula. (Foucault, 2020, p. 28). [el subrayado es mío]

Atendiendo a este vínculo entre la relación de sí y la relación con los otros, Foucault cuestionará el mito de que el sujeto y el objeto de conocimiento (manteniendo esta distinción clásica a los fines de la exposición) no tienen nada que ver, es decir, que el sujeto puede conocer el mundo de forma neutral, independiente y externa, a la manera del "yo" cartesiano, único islote de tierra firme en el mar de la duda. La posición subjetiva pareciera estar legitimada de antemano y, desde allí, puede 
darse a la tarea de conocer el mundo y relacionarse con otros, ignorando el movimiento continuo que establece con múltiples procesos. Así, nuestra tradición filosófica ha separado lo subjetivo de lo objetivo, y ha cultivado la idea de que el individuo no necesita pensar acerca de sí mismo, reflexionar sobre sí mismo, y transformarse a sí mismo para vincularse con los demás, con el mundo y emitir juicios sobre lo real. En Hermenéutica del sujeto, el filósofo afirma que esta convicción era muy evidente para los filósofos antiguos precristianos, pero que ha caído en desuso a partir de la doble herencia del cristianismo y el racionalismo moderno.

Me parece que éste es el punto en que asume su lugar y su sentido lo que llamé el "momento cartesiano", sin querer decir en absoluto que se trata de Descartes, que él fue precisamente su inventor y el primero en hacer esto. Creo que la edad moderna de la historia de la verdad comienza a partir del momento en que lo que permite tener acceso a lo verdadero es el conocimiento mismo, y sólo el conocimiento. Vale decir a partir del momento en que, sin que se le pida ninguna otra cosa, sin que por eso su ser de sujeto se haya modificado o alterado, el filósofo (o el sabio, o simplemente quien busca la verdad) es capaz de reconocer, en sí mismo y por sus meros actos de conocimiento, la verdad, y puede tener acceso a ella. Lo cual no quiere decir, claro está, que la verdad se obtenga sin condiciones. Pero esas condiciones son ahora de dos órdenes, y ninguno de ellos compete a la espiritualidad. (Foucault, 2014 p. 36).

La cita expresa con claridad la problemática desplegada en el presente apartado. La pregunta que surge de esta reflexión es si las prácticas jurídicas no continúan condicionadas por esta separación tajante entre sujeto y objeto, es decir, por un método en el cual los actos de conocimiento, de indagación e interpretación omiten una adecuada consideración de la relación de sí. Desde este punto, no parecen una simple anécdota aquellos ejemplos que utiliza Foucault para reparar en la relevancia que adquiría 
en la filosofía antigua el vínculo entre la preparación de sí y la actividad pública. El filósofo hace uso de un episodio en el cual Séneca elogia a Lucilio por combinar el cargo de Procurador con las conveniencias de desarrollar un arte de sí mismo:

el otium estudioso, en la medida en que es un arte de sí mismo cuyo objetivo es lograr que el individuo establezca consigo mismo una relación adecuada y suficiente, hace que el individuo no lleve su propio yo, su propia subjetividad, al delirio presuntuoso de un poder que desborde sus funciones reales (...) Pero muy pocos hombres son capaces de hacerlo. La mayoría, dice, se afana en el amor por sí mismo o bien en la repugnancia por sí mismos. (Foucault, 2014 b, p. 359-360).

Las ventajas de este arte de sí mismo se revelan a la hora de abstenerse en extralimitar su poder y caer en la trampa de diversos aduladores. La adulación encubre formas de manejo por parte de otros y la sumisión ante los discursos ajenos, que suelen impactar en aquellos individuos que no tienen una relación de sí lo más elaborada posible:

En esta ausencia de soledad, en esa incapacidad de establecer consigo mismo una relación plena, adecuada y suficiente, interviene el Otro, que va a llenar en cierto modo esta laguna, que va a sustituir o mejor dicho a colmar esa inadecuación mediante un discurso (...) El adulado, por la insuficiencia de su relación consigo mismo, queda colocado bajo la dependencia del adulador, adulador que es otro y puede, por tanto, desaparecer, transformar su adulación en maldad, trampa, etc. (Foucault, 2014, p. 361).

Hay una gran riqueza en esta interpretación que hace Foucault del discurso de Séneca. Allí se puede rastrear la vieja preocupación del francés por analizar la función de poder y los efectos de sujeto. Más interesante aún resulta atender al desarrollo de un arte de sí para evitar que el yo se extralimite, esto es, impedir que la propia subjetividad se desborde en la dinámica de su influencia sobre los demás y que, en ese movimiento, 
pueda ser manejada por discursos engañosos y movida hacia una acción cuestionable para con los demás. Se puede extraer de aquí una lección fundamental para el tema de este escrito. En efecto, esta reflexión puede contribuir a desconectar o al menos advertir los efectos espontáneos de un régimen de verdad para emitir juicios sobre los conflictos legales.

\section{III.2. El carácter inevitable de la interpretación jurídica}

Ahora bien, ¿cuál es la importancia de estas ideas para abordar los aspectos más concretos de la interpretación jurídica?

En primer lugar, creo que este análisis conduce a pensar que los presupuestos de un régimen de verdad operan en todas las producciones de una subjetividad. En el ámbito judicial condicionan tanto la emisión de una sentencia, como la producción de un dictamen o un abordaje de la realidad que deriva en la formación de un tipo legal. La reflexión de Foucault, al apartarse de lo que define como "momento cartesiano", invita a considerar una interrelación permanente entre el sujeto y el objeto (entre el interpretante y la ley también manteniendo una distinción clásica). La desconexión de este nudo no se produce nunca. Por lo tanto, cuando el sujeto se piensa de modo trascendente, desconectado de otros procesos y saberes, se pierde de vista su imbricación efectiva con aquello que produce. En otros términos, se oscurece ese proceso mencionado por el cual el "yo" se extralimita y puede reforzar ciertas interpretaciones naturalizadas de la realidad. Si, como dije más arriba, el derecho es una interpretación, desconocer esta implicación, aceptar pasivamente (sin crítica) lo que impone un régimen de veridiccción, conduce a perder de vista la interpretación que se hace de esa interpretación. ${ }^{12} \mathrm{Y}$ esto es un problema delicado,

\footnotetext{
12 En este sentido, es interesante una reflexión de Alejandro Medici cuando señala: "No existe diferencia sustancial entre creación, fundamentación y aplicación del derecho ya que las tres son momentos de interpretación. Las prácticas jurídicas, en tanto tales, son interpretaciones de interpretaciones, re examen de producciones de sentido. No existe, como lo pinta el fetichismo jurídico la norma u el orden normativo en su realidad y objetividad y luego
} 
ya que supone no poder exceder naturalizaciones que la teoría y la práctica del derecho debe poder atravesar.

Se sabe, por ejemplo, que robar constituye una violación a las normas. Pero se condenan con mayor frecuencia algunos sujetos que roban y se deja impune a otros. A nadie se le ocurrió hasta ahora tipificar como un robo los excesos de la especulación financiera a pesar de su comprobado efecto en el detrimento de las economías. Recurriendo a un ejemplo de otro fuero, se sabe que nuestro sistema judicial entiende por compulsivo o adicto a una persona que consume tóxicos y ese criterio generalmente recae sobre aquellas personas que también viven grandes carencias ${ }^{13}$. No obstante, no se nos pasa por la cabeza que un compulsivo pueda ser también alguien que desea acumular y acumular dinero más allá del cualquier consumo posible en una vida humana (incluso en varias) y que entorpece con ese deseo los intentos de generar una economía más igualitaria. No es mi intención hacer un juicio moral sobre estas cuestiones. Sólo pretendo señalar que son ejemplos interesantes para poner de manifiesto el sentido común dominante con el que operan algunas distinciones legales. En esta línea, el caso de la pena ilícita citado al inicio parece constituir un ejemplo típico de formas hegemónicas de interpretar la ley penal que se encuentran consolidadas y ante las cuáles no es sencillo trazar vías de apertura. Es interesante al respecto una

su interpretación. Las normas y el orden jurídico son ya siempre un cierto régimen de enlace histórico entre significantes-significados." (MEDICl, Alejandro (2009). p. 188).

13 Para una interpretación amplia y actual del problema de las adicciones, puede consultarse el trabajo de Ernesto Sinatra Adixiones (2020). Allí el psicoanalista señala que, si bien el consumo de tóxicos es independiente de factores sociales y económicos, no puede negarse que las condiciones sociales actúan como un agravante en este tipo de conductas: "La euforia del flash no deja de ser un lenitivo contra la tristeza, hoy incrementada por la insatisfacción que alimentan la pobreza y el hambre, y si bien se tratan de actos omitidos en la orientación del deseo más allá de las diferencias sociales y económicas, el vértigo del envenenamiento adictivo de la inmediata disforia del paco establece una diferencia mortal. Los individuos afectados por la pobreza están más expuestos a la destrucción por tener una menor red social de contención"(SINATRA, Ernesto (2020). Adixiones, p. 180-181). 
reflexión de Zaffaroni cuando sugiere que el sistema penal tiende a agravar las penas de acuerdo a la situación singular de los bienes lesionados, pero no hace lo propio cuando se trata de disminuir las penas considerando las condiciones sociales, los entrenamientos diferenciales y los estereotipos que sufren quienes infringen la norma:

Hurtar diez vacas siempre será un delito, y sustraerlas de un rodeo de miles de cabezas provoca una lesión incuestionable al patrimonio, pero si se le hurtan las diez vacas lecheras a quien sólo dispone de esos animales para producir leche, venderla y mantener a su familia, sin duda que se produce un daño mayor (...) Así como se debe cuantificar el contenido ilícito del delito tomando en cuenta la pluriofensividad natural de todo conflicto tipificado, también deben tomarse en cuenta las condiciones subjetivas del infractor para determinar el grado de culpabilidad. (Zaffaroni, 2020 b, p.189).

En segundo lugar, esta implicación del sujeto en un acto de interpretación pone de manifiesto que la misma es constitutiva con respecto a la práctica judicial. En otros términos, la interpretación es inevitable. La tradición positivista ha transmitido la idea de que la interpretación sólo se reduce a los pocos casos en los cuales la ambigüedad de la norma no permite ceñirse enteramente a la letra de la ley. La norma sería una herramienta casi perfecta y con un razonamiento deductivo adecuado podría aplicarse estrictamente a la realidad. Sin embargo, los ejemplos anteriores también son útiles para mostrar que el ejercicio del derecho no se encuentra exento de contradicciones conectadas con el régimen de poder y verdad imperante en una sociedad.

En su libro titulado Interpretación Jurídica (2020) el profesor Rabbi Baldi analiza detenidamente esta tendencia del positivismo: "De modo general, el positivismo jurídico consideró el fenómeno interpretativo como una actividad no sólo 'anexa' o 'eventual' esto es, de necesaria excepcionalidad o, si se prefiere, enteramente residual, sino, además, como una tarea peligrosa y hasta ilicita" (Rabbi Baldi, 2020, p. 14). El asunto 
reviste una gran importancia para el tema de este escrito, ya que no reconocer el carácter inevitable de la interpretación puede derivar en una discrecionalidad arbitraria a la hora de intervenir frente a las ambigüedades de la ley. El problema del supuesto positivista es que, ante casos de lagunas normativas o contradicciones en el texto legal, un juez quedaría librado a actuar conforme a su propio criterio, únicamente guiado por sus convicciones morales y políticas (Rabbi Baldi, 2020, p. 32). Conforme lo analizado en el apartado anterior, esta cuestión reviste una singular gravedad por el nivel de imprevisibilidad que le otorgaría a las decisiones judiciales y por la consecuente filtración de prejuicios que pueden redundar en prácticas jurídicas injustas.

Para arrojar luz sobre esta cuestión, el profesor argentino realiza una investigación detallada del fenómeno de la interpretación. A través de la filosofía de Heidegger y Gadamer arriba a un interesante reconocimiento del circulo hermenéutico entre la precompresión como base de cualquier decisión y el sentido que se atribuye al texto legal (Rabbi Baldi, 2020, p. 224). Siguiendo esta lógica, el libro finaliza con una propuesta superadora de la oposición tajante entre un iuspositivismo que sigue a rajatabla la letra la ley y un iusnaturalismo hermenéutico modificador permanente del texto: "Frente a esos extremos, se reivindica en este libro el papel del juez "intérprete", es decir, el que con "fecundo sentido constitucional" optimiza los textos constitucionales haciéndoles rendir frutos más allá de su letra y del momento en que fueron creados" (Rabbi Baldi, 2020, p. 300). El espíritu de este trabajo tiende a coincidir con el tema del presente escrito por cuanto reivindica la interpretación jurídica y procede a considerar la intervención de los prejuicios del interprete en la decisión judicial.

No obstante, considero que no ahonda lo suficiente en la constitución relacional de la entidad subjetiva vinculada a diferentes regímenes de verdad. El argumento de Rabbi Baldi mantiene en muchos de sus tramos los supuestos de la ética 
comunicativa y la racionalidad práctica de autores como Alexy, Atienza, Apel y Habermas (Cf. Rabbi Baldi, 2020, p. 107). También se apuntala con aspectos del iusnaturalismo de Santo Tomás para pensar el proceso judicial como instancia superadora de diálogo (Cf. Rabbi Baldi, 2020, p. 116) y de la costumbre como fundamento del derecho (Cf. Rabbi Baldi, p. 125). Sin negar la relevancia de estas posturas, el presente escrito se propone evitar el recurso a este tipo apriorismo tanto en su aspecto metodológico, como en el referido a la fundamentación de los procesos y la entidad de los agentes que intervienen. La explicación para esta decisión radica en la sencilla razón de que esa vía puede oscurecer los vínculos efectivos y materiales entre las instituciones, las subjetividades y las relaciones de poder. Entiendo que estas formas de naturalismo merecen ser problematizadas si se aspira a una mirada crítica hacia las imposiciones que generan los regímenes de verdad. Al respecto resulta interesante una opinión que ya el propio Foucault esgrimía ante las críticas de Habermas. El francés no se mostraba totalmente en desacuerdo con los fines éticos perseguidos por el pensador alemán. Nadie en su sano juicio negaría que es mejor sentarse a hablar un problema que entregarse a su resolución violenta. Tampoco podría negarse la importancia del derecho como resolución razonada de conflictos. Sin embargo, Foucault sí mantenía algunos reparos respecto al utopismo de la propuesta habermasiana por la razón de que parte de una consideración un tanto ideal del entendimiento comunicativo que desconoce las posiciones diferenciales y las relaciones de poder reales que operan en el campo social e intersubjetivo. Al respecto, vale la pena considerar esta observación que hace Foucault en una entrevista que ya he citado:

Sin duda me intereso por lo que hace Habermas y sé que no está en absoluto de acuerdo con lo que digo - yo estoy un poco más de acuerdo con lo que él dice-, pero hay sin embargo, algo que para mí constituye siempre un problema: es cuando él otorga a las relaciones de comunicación este lugar tan importante y, sobre todo, 
una función que llamaría utópica. La idea de que podrá existir un estado de comunicación de tal índole que los juegos de verdad puedan circular en él sin obstáculos, sin coacciones y sin efectos coercitivos, me parecen del orden de la utopía. (Foucault, 1999, p .412).

Por otro lado, se puede destacar que la concepción foucaulteana promueve no sólo el reconocimiento de los prejuicios que anidan en una interpretación, sino que da un paso más sugiriendo una ascesis, es decir, un modo de abordar la relación de sí en vistas a evitar las extralimitaciones del "yo" que puedan crear una relación opresiva para consigo mismo y con los demás. No es este el lugar para abordar en detalle este punto de la obra del francés, pero puede el lector si le interesa consultar mucha bibliografía respecto a este punto ${ }^{14}$. Me limitaré decir que, en la línea de ese arte de sí mismo mencionado más arriba, los últimos momentos de la reflexión foucaulteana giran en torno a la constitución de una subjetividad ética capaz de establecer una relación de sí plena y abierta a los demás sin recurrir a ninguna utopía, ningún universal antropológico y desde una aceptación cabal de los juegos estratégicos de poder.

Por último, y atendiendo precisamente a esta cuestión estratégica, la filosofía de Foucault ofrece un poderoso método para la comprensión de la trama relacional que interviene en el fenómeno interpretativo. En esta línea, considerar esas relaciones entre los saberes, las relaciones de poder, y la subjetividad, invita a formar una concepción integral de los factores que entran en juego. Es sabido que, muchas veces, tanto la creación de nuevos tipos legales, como las sentencias de los magistrados $\mathrm{y}$, por ende, las argumentaciones de las partes en

\footnotetext{
14 Entre algunos trabajos ya consagrados se encuentran CASTRO ORELLANA, Rodrigo (2006). Ética para un rostro de arena: Michel Foucault y el cuidado de la libertad. Tesis doctoral; también se destaca el trabajo del alemán SCHIMDT, Wilhelm (2002). En busca de un nuevo arte de vivir. La pregunta por el fundamento y la nueva fundamentación de la ética en Foucault. Entre los más recientes se podría destacar: SAUQUILLO, Julián (2016). Subjetividad y verdad: el recorrido de Michel Foucault en el College de France, y en el contexto nacional FARRAN, Roque (2018). El uso de los saberes.
} 
un proceso están fuertemente condicionadas por la opinión pública y el interés de los medios de comunicación. El temor a los costos políticos ante una interpretación que no siga al pie de la letra los dictados de la mirada hegemónica constituye un problema permanente. El concepto de "puerta giratoria de los delincuentes", una interpretación estimulada por los medios, que manipula hábilmente el desconocimiento general acerca de las fundamentaciones sobre el debido proceso, es un ejemplo muy común que deriva en el incremento del poder punitivo descargado sobre ciertos sectores. Este tipo de presiones son cruciales para pensar la interpretación jurídica. Dependiendo de la situación particular, la presión de las relaciones puede adquirir dos formas peligrosas por sus consecuencias: o bien pueden generar una interpretación apegada estrictamente al texto de la ley, es decir, cuando un magistrado teme que los costos políticos de una decisión discrecional puedan ser muy grandes. En ese sentido surgen decisiones que descargan poder punitivo sobre sectores vulnerables y no tanto sobre otros sectores; o bien, una interpretación que hace uso de una gran discrecionalidad y que no esta tan apegada al texto de la ley. Por ejemplo, el mencionado caso de la prisión preventiva. Aun siendo esta forma procesal de aplicación singular cuando hay pruebas de que el acusado pueda entorpecer el proceso, suele utilizarse como una manera de dar un castigo sin juicio para evitar, entre otras cosas, la sentencia mediática que acusa a los jueces de ser demasiado flexibles. Frente a estas cuestiones, resuenan con una fuerza particular esas dependencias ante los discursos de Otros (señalado más arriba a propósito de Séneca) que pueden desestabilizar las decisiones adecuadas. $\mathrm{Y}$ ante esas formas de discurso se aprecia la necesidad de una formación integral de quienes tienen en sus manos la administración del derecho. Esta formación, por supuesto que depende de la calidad técnica y jurídica del agente en cuestión, pero no se limitan a eso, sino también a la preparación en cuestiones de otra índole que apuntan a saber qué hacer y cómo posicionarse ante el avance de discursos engañosos. 
Siguiendo esta lógica, el presente escrito concibe la interpretación jurídica de un modo amplio que atañe tanto a la que realizan del texto de las leyes abogados, magistrados y demás agentes judiciales, como aquellas que hacen de la realidad otros agentes sociales y que deriva en la creación de nuevos tipos legales. Es cierto que un análisis pormenorizado de la racionalidad legal implicaría separar lo que corresponde a la legislación de una ley y al proceso de deducción y aplicación de la misma (diferencia entre la racionalidad legislativa y la judicial). En su texto Argumentación legislativa (2019) el filósofo Manuel Atienza aborda con detalles esta distinción. Sin embargo, las herramientas elaboradas en el presente escrito se aplican en ambas dimensiones. Tanto en una como en otra intervienen los presupuestos de un régimen de verdad. En un caso para pensar la creación o reinterpretación de ciertos tipos y, en otro, operando en las decisiones que se toman para la aplicación de los mismos.

\section{Conclusiones}

La hipótesis central de este trabajo consistió en mostrar que la filosofía del derecho debe pensar seriamente el nudo señalado entre las verdades que orientan la acción de un sujeto, el modo en que el mismo se vincula con las normas, y los juicios que emite acerca de los demás. Si este vínculo es idealista y no atiende a la materialidad del nudo señalado, la práctica del derecho puede devenir en mero formalismo funcional a intereses corporizados. Desde esta convicción, creo que el enfoque abordado permite desarrollar una concepción de la interpretación jurídica estrechamente vinculada al desarrollo de un sujeto ético, es decir, un ser capaz de posicionarse críticamente ante los excesos de un régimen de verdad dominante. En este sentido, permite superar a un tiempo dos extremos: por un lado, los riesgos del antiguo derecho natural, basado en ideas sustanciales acerca de los procesos legales y el contenido de la persona humana, que pueden convertirse en formas de legitimar 
ciertas diferencias; por otro, permite problematizar también la neutralidad positivista, ofreciendo un modo de reflexión crítica acerca de los presupuestos de un régimen de verdad y poder.

Alejándose de estos extremos, la línea propuesta puede ser útil para realizar una vigilancia permanente sobre el fenómeno interpretativo con el objetivo de evitar o, al menos, comprender cabalmente aquellos elementos que se filtran de modo constitutivo en la creación y la interpretación de los tipos legales. Considero que esta es una dimensión práctica de la reflexión que puede contribuir a un efectivo reconocimiento de los demás seres. En efecto, subyace a este planteo una filosofía del sujeto relacional, que no postula ningún contenido esencial sobre la substancia de la persona, sino que invita a considerar y respetar a los demás en la paradoja de su constitución singular y de su deseo irreductible. ${ }^{15}$ Creo que uno de los ejemplos más recientes en esta línea, podría encontrarse en la despenalización de la interrupción del embarazo alcanzada en la Argentina en diciembre de 2020. Esta conquista en materia de derechos supuso una reinterpretación radical de un antiguo tipo penal hecha en función de un reconocimiento de la condición singular de muchas mujeres. Para su abolición fue necesario un largo proceso de lucha y crítica hacia las imposiciones del patriarcado como régimen de verdad.

Por otra parte, es cierto que, así como siempre va a existir un vacío en un sistema de leyes (incompletitud propia de todo sistema) siempre va a emerger la singularidad de un sujeto en toda interpretación. Por esa razón, se puede decir que en esta hipótesis subyace también un vínculo particular entre filosofía,

15 En un trabajo anterior he analizado con más detalle el "contenido" de los derechos que podrían deducirse de la filosofía de Foucault: “. .. creo que el argumento que he expuesto en el presente trabajo puede contribuir a promover un ejercicio del derecho que no se piensa desde un lugar más fundamental (ya sea trascendental o trascendente) 0 desde la defensa de algún principio de superioridad étnica, racial, nacional, racional, etc. Por el contrario, se define en una relación de inmanencia respecto a los procesos sociales y sin una postulación esencial con respecto a su contenido." (Autor, 2019, p. 244). 
derecho y psicoanálisis. El proceso de advertir y reconocer este anudamiento entre la subjetividad, la verdad y el poder, constituye un paso imprescindible para evitar caer en interpretaciones jurídicas que pueden ser injustas. Lacan, por ejemplo, sostenía que sólo un reconocimiento del síntoma puede romper la implicación entre el individuo y su conducta, es decir, cuestionar los efectos de su trama vivencial espontánea e inconsciente. ${ }^{16}$ En consecuencia, considero que estudiar el nudo constituido por estas dimensiones podría aportar cambios significativos en el modo en el que se piensa y realiza la tarea judicial.

Por último, si hay una cláusula consagrada de los derechos humanos que establece que una persona no puede ser juzgada por un juez dependiente (Slokar, 2020, p. 2; DUDH Art. 10), también sería deseable, por el espíritu de dicho principio, que un juez afine, trabaje y reflexione en esta relación consigo mismo para no caer en dependencias más profundas con algunos intereses, prácticas y supuestos naturalizados. Si, por otra parte, se afirma que las sentencias son actos políticos (Zaffaroni, 2019, p. 46; Slokar, 2020, p. 2-3) sería preciso señalar que también son interpretaciones subjetivas, y reflexionar, desde los tramos formativos y prácticos del derecho, sobre esta compleja relación entre el poder, el sujeto y la interpretación jurídica.

\footnotetext{
16 "El sujeto tiene que darse cuenta de que eso funciona así. Este reconocimiento no es un efecto separado del funcionamiento de este síntoma, no es epifenomenal. El síntoma sólo queda constituído cuando el sujeto se percata de él (...) Tan sólo por este lado se rompe la implicación del sujeto en su conducta, y esa ruptura es la complementación necesaria para que el síntoma sea abordable para nosotros. Este signo no constituye sólo un paso en lo que podría ser la inteligencia de la situación, es algo más, que es esencial en la cura de la obsesión." (LACAN, Jacques, 2007. p.303).
} 